\title{
Phytoplankton community structures in Fushan Bay
}

\section{Dongfang Yang ${ }^{1,2,3, a}$, Fengyou Wang ${ }^{1,2, b}$, Xiuqin Yang $^{1,2}$, Xiaoli Zhao ${ }^{1,2}$ and Sixi Zhu ${ }^{1,2}$}

\author{
${ }^{1}$ Research Center for Karst Wetland Ecology, Guizhou Minzu University, Guiyang 550025, China; \\ ${ }^{2}$ College of Chemistry and Environmental Science, Guizhou Minzu University, Guiyang 550025, \\ China; \\ ${ }^{3}$ North China Sea Environmental Monitoring Center, SOA, Qingdao 266033, China. \\ adfyang_dfyang@126.com, bcorresponding author fywang@163.com
}

Keywords: Phytoplankton, Community structure, Silicon, Nutrient, Fushan Bay.

\begin{abstract}
This paper analyzed the community structures of phytoplankton in Fushan Bay in June to August 2002. Results showed that phytoplankton in Fushan Bay was dominated by Bacillariophyta and Pyrrophyta, whose species accounted for $74 \%$ and $24 \%$ of total phytoplankton species, respectively. Chaetoceros and Peridinium were the major genera of Bacillariophyta and Pyrrophyta, accounted for $19 \%$ and $44 \%$ for Bacillariophyta and Pyrrophyta, respectively. There were something in common between phytoplankton community structures of Fushan Seas, Guangzhou Seas and Hongkong Seas. Firstly, Bacillariophyta and Pyrrophyta were the dominant and subdominant phyla in Seas in different latitude. Secondly, the proportions of the species of Bacillariophyta and Pyrrophyta were consistent in Seas in different latitude. These features were determined by nutrient Silicon.
\end{abstract}

\section{Introduction}

Phytoplankton is the basis of marine food chain, and is playing an important role in atmospheric $\mathrm{CO}_{2}$ removing [1]. Previous studies showed that Silicon was the limited factor of the primary productivity in Jiaozhou Bay, China [2]. Based on the researches of the influences of Silicon in the growth, physiological feature and community structure of phytoplankton, we found that Silicon was the limited factor of phytoplankton in ocean [3], and the growth of phytoplankton determined the balance of atmospheric $\mathrm{CO}_{2}[4-5]$.

Studying the community structure of phytoplankton is meaningful in marine ecosystem and climate change. Based on investigation data on phytoplankton in Fushan Bay in June to August 2002, this paper analyzed the phytoplankton community structure Fushan Bay. Moreover, a comparison study on phytoplankton community structures between Fushan Seas, Guangzhou Seas and Hongkong Seas was provided to reveal the spatial variations of phytoplankton community structures.

\section{Material and method}

Loushan Bay $\left(36^{\circ} 00^{\prime}-36^{\circ} 06^{\prime} \mathrm{N}, 120^{\circ} 29^{\prime}-120^{\circ} 42^{\prime} \mathrm{E}\right)$ is located in the south of Qingdao, Shandong Province, China (Fig. 1). The water depth and coastline are 9-30 $\mathrm{m}$ and $7 \mathrm{~km}$, respectively. The data was provided by North China Sea Environmental Monitoring Center. Eleven monitoring sites were set up, and the survey was conducted in June, July, August and September 2002. The sampling method of phytoplankton was followed by National Specification for Marine Monitoring [6], and the species identification of phytoplankton was follow by Hu et al. [7]. 


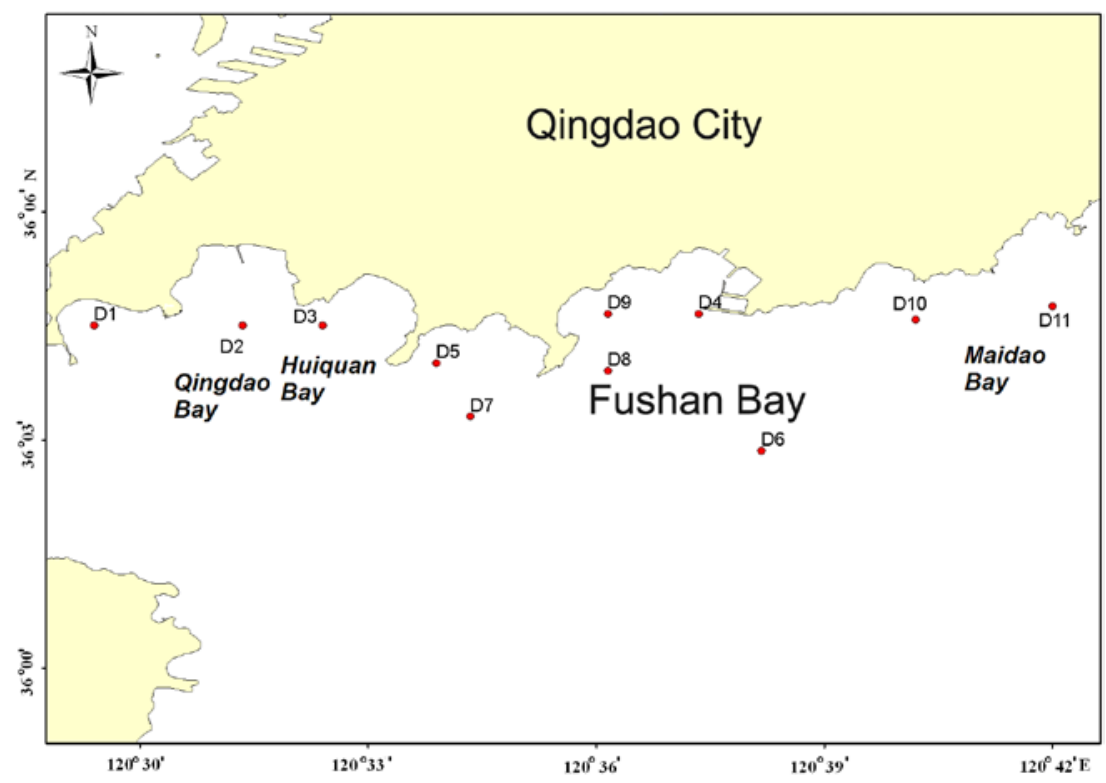

Fig.1 Investigation sites in Fushan Bay

\section{Results and discussion}

Proportions of species for different phyla. There were 4 phyla, 39 genera and 102 species in study Fushan Bay in June to September 2002, including Bacillariophyta, Pyrrophyta, Chlorophyta and Chrysophyta, accounted for 74\%, 24\%, 1\% and 1\% for all of the 102 species (Fig. 2). It could be seen that the number of the phytoplankton species was relative high in Fushan Bay in 2002, and the phytoplankton community structure was also relative stable. Obviously, phytoplankton in Fushan Bay was dominated by Bacillariophyta and Pyrrophyta.

Chaetoceros, Coscinodiscus, Rhizosolenia, Nitzschia and Pleurosigma were the major genera for Bacillariophyta phyla, accounted for 19\%, 14\%, 10\%, $7 \%$ and $5 \%$ for the species of Bacillariophyta (Fig. 3). While for Pyrrophyta phyla, Peridinium, Ceratium and Noctiluca were the major genera, accounted for 44\%, 28\% and 8\% for the species of Pyrrophyta (Fig. 4).

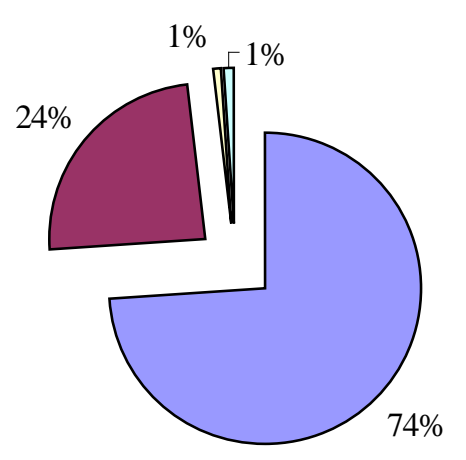

$\square$ Bacillariophyta

$\square$ Pyrrophyta

$\square$ Chlorophyta

口Chrysophyta

Fig.2 The proportion of different phyla for species 


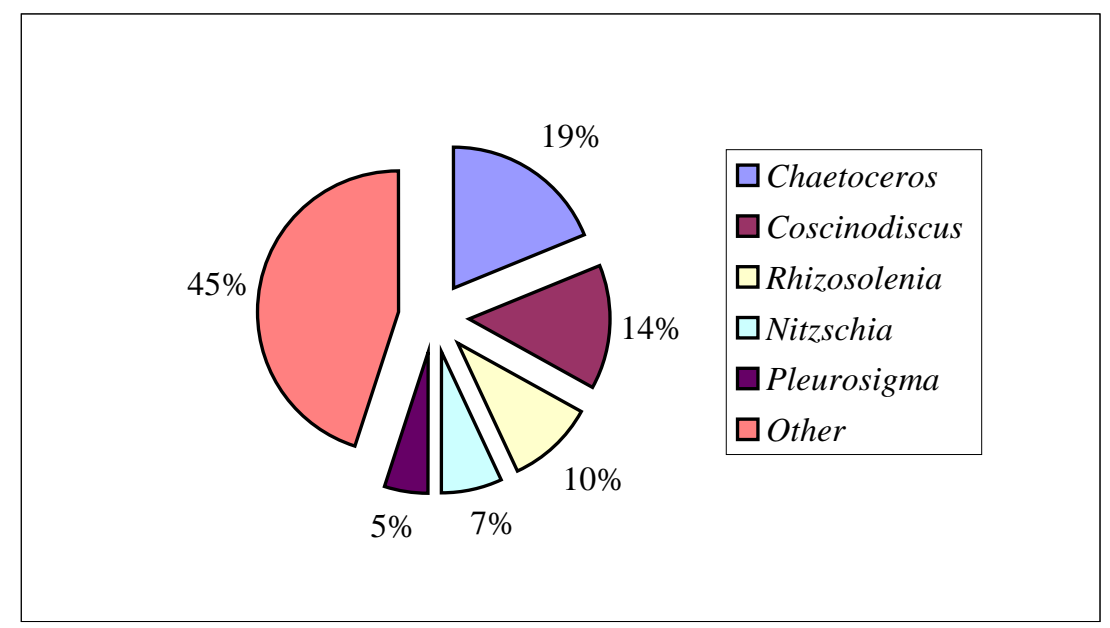

Fig. 3 The proportions of different genera for species in Bacillariophyta phyla

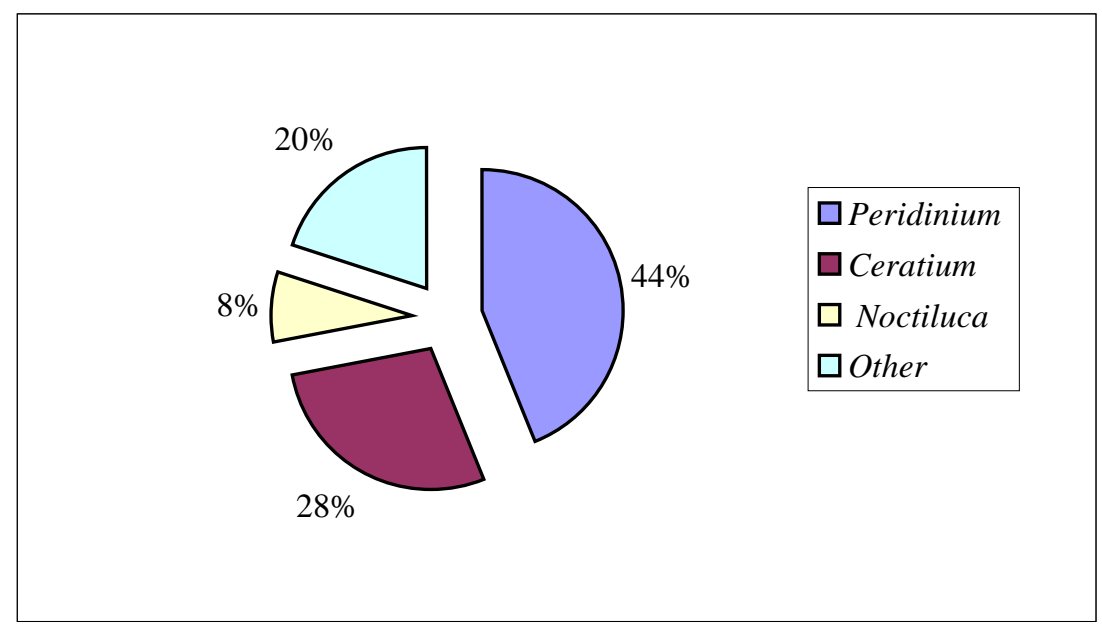

Fig. 4 The proportions of different genera for species in Pyrrophyta phyla

Spatial variations of phytoplankton community structures in different Seas. In order to reveal the spatial variations of phytoplankton community structures, comparison study on phytoplankton community structures between Fushan Seas, Guangzhou Seas and Hongkong Seas was provided. There were 89 genera and 209 species in Guangzhou Seas in May 2003 to May 2004, in which Bacillariophyta accounted for 55\% of the species [8]. For Hongkong Seas in 2004, there were 48 genera and 139 species, in which Bacillariophyta and Pyrrophyta accounted for $71 \%$ and $25 \%$ of the species [9]. These results confirmed the viewpoint of Yang et al. [10-12] that Bacillariophyta was the dominant phyla in global ocean. Pyrrophyta was the subdominant accounted for 24\% and 25\% of the phyla in Fushan Seas and Hongkong Seas.

Silicon determined the proportions of species for Bacillariophyta and Pyrrophyta. Soluble inorganic silicon is one of the essential nutrients for marine phytoplankton, having close relations to the structure and metabolism of Bacillariophyta, and is controlling the growing process of phytoplankton [13-14]. $\mathrm{Si}(\mathrm{OH})_{4}$ plays a core role in the algal bloom [15]. Silicon is the limited factor of the primary productivity of phytoplankton, especially for the growth of Bacillariophyta [16-19]. In generally, Silicon is the engine for the growth of phytoplankton, having strong and rapid influence on the growth of phytoplankton [17], and therefore is the limited factor of the global ocean phytoplankton [18]. The surface water temperature of Fushan Seas and Hongkong Seas were $2-24^{\circ} \mathrm{C}$ (13 ${ }^{\circ} \mathrm{Cn}$ average) and $18-29^{\circ} \mathrm{C}\left(26^{\circ} \mathrm{C}\right.$ in average), respectively. However, both the proportions of species of Bacillariophyta and Pyrrophyta were closed. Based on previous researches by Yang et al., such as the factor and way of limiting nutrient for the growth of phytoplankton [20], the uniqueness of nutrient limitation [11], and magnitude order of the effect of light, water temperature and nutrients on phytoplankton growth [12], it could be concluded that these features were determined by Silicon. 


\section{Conclusion}

Phytoplankton in Fushan Bay was dominated by Bacillariophyta and Pyrrophyta, accounted for $74 \%$ and $24 \%$ for the species. Chaetoceros, Coscinodiscus, Rhizosolenia, Nitzschia and Pleurosigma were the major genera for Bacillariophyta phyla. For Pyrrophyta phyla, Peridinium, Ceratium and Noctiluca were the major genera. Both the proportions of species of Bacillariophyta and Pyrrophyta in Fushan Seas and Hongkong Seas were closed, these features were determined by Silicon.

\section{Acknowledgement}

This research was sponsored by Ocean Public Welfare Scientific Research Project, State Oceanic Administration of China (No. 201005014) and Scientific Research Funds of the State Oceanic Administration of the North Sea Monitoring Center (No. 05EMC16).

\section{References}

[1] Yang DF, Wu JP, Qu YF et al.: Adv. Mar. Sci., Vol. 25 (2007), p. 117-122. (in Chinese)

[2] Yang DF, Zhang J, Lu JB, et al.: Chin. J Oceanol. Limnol., Vol. 20 (2002), p. 208-225.

[3] Yang DF, Yin YF, Sun JY, et al.: Mar. Sci., Vol. 28 (2009), p. 100-117. (in Chinese)

[4] Yang DF, Miao ZQ, Shi Q, et al.: Chin. J. Oceanol. Limnol., Vol. 28 (2010), p. 416-425 .

[5] Yang DF, Miao ZQ, Chen Y, et al.: Atmos. Clim. Sci., Vol. 1(2011), p. 189-196.

[6] China's State Oceanic Administration: The specification for marine monitoring (Ocean Press, Beijiang 1991). (in Chinese)

[7] $\mathrm{Hu} \mathrm{HJ}, \mathrm{Li} \mathrm{YY}$, Wei YX, et al.: Chinese freshwater algae (Environmental Science Press, Shanghai 1979). (in Chinese)

[8] Feng JP, Jiang S, Feng JH, et al.: Ecolog. Sci., Vol. 25 (2006), p.210-212. (in Chinese)

[9] Lin XY, Xing XL,He JZ, et al.: Mar. Sci. Bull., Vol. 27 (2008), p.23-29.(in Chinese)

[10] Yang DF, Yu ZJ, Zhang K, et al.: Mar. Environ. Sci., Vol. 27 (2008), p.547-553(in Chinese)

[11] Yang DF, Zhang J, Chen Y, et al.: Mar. Sci., Vol. 25 (2001), p. 49-51. (in Chinese)

[12] Yang DF, Chen ST, Hu J, et al.:Mar. Environ. Sci., Vol. 26 (2007), p.201-207(in Chinese)

[13]Dugdale RC, Wilkerson FP and Minas HJ: Deep-Sea Res(I), Vol. 42 (1995), p. 697-719.

[14]Sakshaug E, Slagstad D and Holm-Hansen O:Mar. Chem., Vol.35 (1991), p.259-271.

[15]Conley DJ and Malone TC: Mar. Ecol. Prog. Ser., Vol. 81(1992), p. 121-128.

[16]Brzezinski MA, Olson RJ and Chisholm SW: Mar. Ecol. Prog. Ser., Vol. 67 (1990), p.83-96.

[17]Brzezinski MA: J Plankton Res., Vol. 14 (1992), p.1511-1536.

[18]Lewin JC. Silicification. In:Physiology and biochemistry of the algae. Lewin R E, editor, (Academic Press 1962), p. 445-455.

[19] Yang DF, Gao ZH, Wang PG, et al.:Mar. Environ. Sci., Vol. 25 (2006), p. 1-6. (in Chinese) [20]Yang DF, Li H, Zhang YM, et al.:Mar. Sci., Vol. 24 (2000), p. 47-50. 